Subscriber access provided by Caltech Library

\title{
Communication
}

\section{Operando Spectroscopic Analysis of CoP Films Electrocatalyzing the Hydrogen-Evolution Reaction}

Fadl Hussein Saadi, Azhar I. Carim, Walter S. Drisdell, Sheraz Gul, Jack Hess Baricuatro, Junko Yano, Manuel P. Soriaga, and Nathan S. Lewis

J. Am. Chem. Soc., Just Accepted Manuscript • DOI: 10.1021/jacs.7b07606 • Publication Date (Web): 28 Aug 2017

Downloaded from http://pubs.acs.org on August 29, 2017

\section{Just Accepted}

"Just Accepted" manuscripts have been peer-reviewed and accepted for publication. They are posted online prior to technical editing, formatting for publication and author proofing. The American Chemical Society provides "Just Accepted" as a free service to the research community to expedite the dissemination of scientific material as soon as possible after acceptance. "Just Accepted" manuscripts appear in full in PDF format accompanied by an HTML abstract. "Just Accepted" manuscripts have been fully peer reviewed, but should not be considered the official version of record. They are accessible to all readers and citable by the Digital Object Identifier (DOI®). "Just Accepted" is an optional service offered to authors. Therefore, the "Just Accepted" Web site may not include all articles that will be published in the journal. After a manuscript is technically edited and formatted, it will be removed from the "Just Accepted" Web site and published as an ASAP article. Note that technical editing may introduce minor changes to the manuscript text and/or graphics which could affect content, and all legal disclaimers and ethical guidelines that apply to the journal pertain. ACS cannot be held responsible for errors or consequences arising from the use of information contained in these "Just Accepted" manuscripts. 
The electrolytic decomposition of water to produce $\mathrm{H}_{2}$ can provide a sustainable, carbon-neutral source of chemical fuel, provided that the input energy is obtained from a renewable source. ${ }^{1,2}$ Electrolytic $\mathrm{H}_{2}$ production can compensate for the intermittency of solar and wind resources by storing energy in hydrogen molecules, which could be used upon demand. ${ }^{3}$

At many non-noble-metal cathode surfaces, the electrochemical half-reaction for the electrolytic production of $\mathrm{H}_{2}$ from water, the hydrogen-evolution reaction (HER), does not proceed effectively in acidic media. Hence energy inputs that substantially exceed the thermodynamic value (overpotentials, $\eta$ ) must typically be utilized to generate $\mathrm{H}_{2}$ at rapid rates (i.e. current densities). ${ }^{4-6}$ The discovery of active HER electrocatalysts comprised of inexpensive and earth-abundant materials is thus being vigorously pursued. $^{7-9} \mathrm{Ni}$ metal and $\mathrm{Ni}$ alloys are effective HER catalysts in alkaline media, but are susceptible to chemical corrosion in acidic electrolytes. ${ }^{10-12}$ Electrocatalysts that are stable under operation in acidic media could be integrated into devices that utilize protonexchange membrane (PEM) technologies, which have advantages relative to device designs that operate in alkaline media, including lower ohmic loss, lower gas crossover, and production of $\mathrm{H}_{2}(\mathrm{~g})$ under high pressure. ${ }^{13}$

\begin{abstract}
Transition metal phosphides exhibit high catalytic activity towards the electrochemical hydrogen-evolution reaction (HER) and resist chemical corrosion in acidic solutions. For extial, $\eta$, of $-\eta<100 \mathrm{mV}$ at a current density of $-10 \mathrm{~mA} \mathrm{~cm}{ }^{-2}$ in 0.500 $\mathrm{M} \mathrm{H}_{2} \mathrm{SO}_{4}(\mathrm{aq})$. To obtain a chemical description of the matesuch electrocatalyst films were investigated using Raman specas under in-situ and operando conditions in $0.500 \mathrm{M} \mathrm{H}_{2} \mathrm{SO}_{4}$ (aq). Ex-situ analysis using the tandem spectroscopies indicated the presence of multiple ordered and disordered phases that contained
both near-zero valent and oxidized Co species, in addition to reduced and oxygenated $\mathrm{P}$ species. Operando analysis indicated that the active electrocatalyst was primarily amorphous and predominantly consisted of near-zero-valent Co as well as reduced P.
\end{abstract}

Nanoparticulate $\mathrm{Ni}_{2} \mathrm{P}$ is an effective, acid-stable HER catalyst. ${ }^{14}$ This observation has prompted substantial, sustained efforts to synthesize and develop other transition metal phosphide materials and to engineer such materials for maximum catalytic HER activity. ${ }^{15-19}$ Electrodeposited CoP films effect the HER at a current density of $-10 \mathrm{~mA} \mathrm{~cm}{ }^{-2}$ with $-\eta<100 \mathrm{mV}$ in acidic solution $(\mathrm{pH}<1) .{ }^{20}$ Characterization of this material, as well as related metal phosphides, has relied principally upon ex-situ techniques that typically involve analysis in vacuum or laboratory ambients. Herein, electrodeposited $\mathrm{CoP}$ films have been investigated under in-situ and operando conditions using Raman spectroscopy and Co and $\mathrm{P}$ K-edge X-ray absorption spectroscopy (XAS), including analysis of the resulting X-ray absorption nearedge structure (XANES) and extended X-ray absorption fine structure (EXAFS) data.

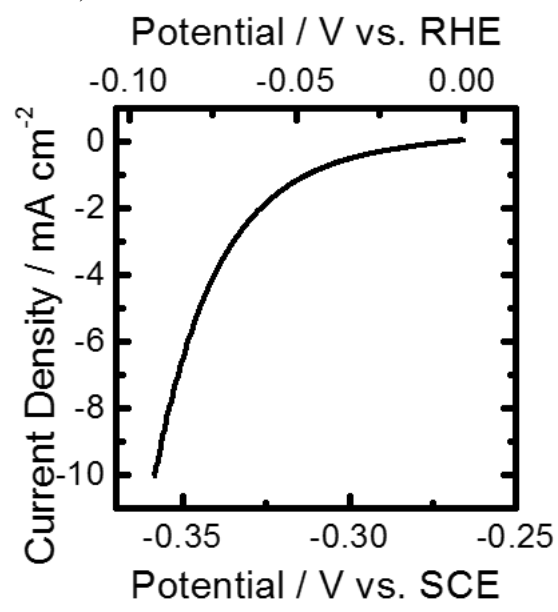

Figure 1. Cathodic polarization behavior of a $\mathrm{CoP}$ film in 0.500 $\mathrm{M} \mathrm{H}_{2} \mathrm{SO}_{4}(\mathrm{aq})$.

Electrocatalyst films were deposited potentiostatically onto planar $\mathrm{Cu}$ substrates, using an aqueous solution that contained $\mathrm{CoCl}_{2}$ and $\mathrm{NaPO}_{2} \mathrm{H}_{2}$. Voltammetric, in-situ, and operando spectroscopic analyses were then performed in $0.500 \mathrm{M} \mathrm{H}_{2} \mathrm{SO}_{4}(\mathrm{aq})$ (experimental methods are described in detail in the online Supporting Information). The steady-state voltammetric response (Figure 1) indicated that production of cathodic current densities 
of 0.5 and $10 \mathrm{~mA} \mathrm{~cm}^{-2}$ required overpotentials of -34 and $-92 \mathrm{mV}$ (applied biases of $-0.300 \mathrm{~V}$ and $-0.358 \mathrm{~V}$ vs. a saturated calomel electrode [SCE]), respectively (Figure 1). Figure 2a presents an ex-situ Raman spectrum of an as-deposited electrocatalyst film. The broad band centered at $595 \mathrm{~cm}^{-1}$ is indicative of amorphous

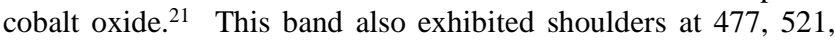
and $677 \mathrm{~cm}^{-1}$, which correspond to $\mathrm{Co}_{3} \mathrm{O}_{4}$ phonon modes. ${ }^{22}$ The Raman modes observed in the $970-1200 \mathrm{~cm}^{-1}$ spectral region are consistent with P-O stretching vibrations in a disordered system. ${ }^{23,24}$ Prior X-ray photoelectron spectroscopic (XPS) analysis indicated the presence of $\mathrm{Co}$ metal, $\mathrm{Co}_{3} \mathrm{O}_{4}, \mathrm{Co}_{3}\left(\mathrm{PO}_{4}\right)_{2}$, as well as $\mathrm{CoP}$ in the as-deposited electrocatalyst film. ${ }^{20}$ Moreover, the XPS analysis as well as prior energy-dispersive X-ray spectroscopic (EDS) analysis, indicated a Co:P elemental ratio in large excess of the 1:1 ratio expected for stoichiometric CoP, in accord with expectations that a substantial amount of Co species is not in the reduced phosphide state. ${ }^{20}$ The Raman data presented herein are thus consistent with the prior XPS and EDS analyses.
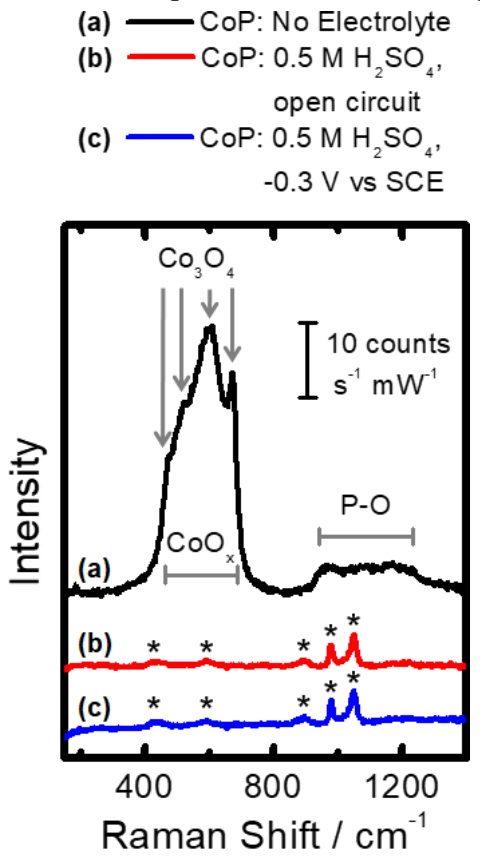

Figure 2. Raman spectra of CoP films. (a) Spectrum of a CoP film prior to contact with $\mathrm{H}_{2} \mathrm{SO}_{4}(\mathrm{aq})$ (air ambient, ex-situ). (b) CoP film in $0.500 \mathrm{M} \mathrm{H}_{2} \mathrm{SO}_{4}(\mathrm{aq}$ ) at open circuit (in-situ). (c) Same as (b) but at an applied potential of $-0.300 \mathrm{~V}$ vs. SCE (operando). Spectral features consistent with amorphous $\mathrm{CoO}_{\mathrm{x}}$ and crystalline $\mathrm{Co}_{3} \mathrm{O}_{4}$ phonon scattering and $\mathrm{P}-\mathrm{O}$ stretching vibrations are labeled as such. * indicates spectral features consistent with scattering from the $\mathrm{H}_{2} \mathrm{SO}_{4}(\mathrm{aq})$ electrolyte.

The same as-deposited electrocatalyst film was then immersed in $0.500 \mathrm{M} \mathrm{H}_{2} \mathrm{SO}_{4}(\mathrm{aq})$ and an in-situ Raman spectrum was collected without an applied bias (open-circuit conditions; Figure 2b). The observed Raman modes centered at 429, 587, 896, 980, $1054 \mathrm{~cm}^{-1}$ are consistent with scattering from the aqueous $\mathrm{H}_{2} \mathrm{SO}_{4}$ electrolyte. ${ }^{25,26}$ No other signals were observed, including those that correlated with oxidized Co and P species in the ex-situ Raman spectrum. After collection of the in-situ spectrum, a potential of $-0.300 \mathrm{~V}$ vs. SCE was applied to the film such that the HER was being actively catalyzed, and an operando Raman spectrum was acquired (Figure 2c). The operando spectrum was nearly identical to the in-situ spectrum. Before and after collection of both the in-situ and operando spectra, substantial reflected excitation intensity was observed in a well-defined spot that was $<10$ $\mu \mathrm{m}$ in diameter, consistent with the high numerical aperture of the objective in the Raman microprobe, indicating that the electrode interface was being interrogated throughout these analyses. Figure S1 presents an ex-situ Raman spectrum of crystalline CoP reference material, which exhibited several detectable signals at small Raman shifts consistent with phonon scattering in a crystalline material. The lack of observed phonon scattering in the in-situ and operando spectra is thus consistent with the amorphous nature of electrodeposited $\mathrm{CoP}$ as well as with the Pourbaix instability of oxidized cobalt species in strongly acidic media. ${ }^{20,27}$ Additionally, prior $e x$-situ XPS analysis of catalyst films after cathodic polarization in the HER regime in $0.500 \mathrm{M} \mathrm{H}_{2} \mathrm{SO}_{4}(\mathrm{aq})$ displayed strong signals attributable to $\mathrm{CoP}$ while signals corresponding to both metallic and oxidized Co were not observed. ${ }^{20}$ These XPS data, as well as analogous prior EDS data, also indicated a Co:P elemental ratio of $1: 1$, suggesting the removal of the elemental excess of $\mathrm{Co}$ observed using these techniques in the as-prepared film. ${ }^{20}$ The film composition was thus consistent with the removal of the Pourbaix unstable metallic and oxidized Co species in $0.500 \mathrm{M}$ $\mathrm{H}_{2} \mathrm{SO}_{4}(\mathrm{aq})$. Hence, the results of the in-situ and operando Raman analysis are supported by the prior ex-situ XPS and EDS analyses after electrocatalytic operation.

To further elucidate the elemental oxidation states in the active electrocatalyst, Co K-edge and P K-edge XAS data were obtained in a manner analogous to the Raman investigation. The X-rays entered the electrochemical cell through the back of the catalyst film and thus provided a bulk probe of the entire film thickness. The acquired spectra thus represent the sum of signals originating from the material at the solution interface as well as all the material extending to the $\mathrm{Cu}$ substrate. This is similar to the Raman experiment where although the optical excitation was incident from the front towards the electrocatalyst-solution interface, the acquired spectra were derived from scatter generated both at and below the interface. Figure $3 \mathrm{a}-\mathrm{c}$ presents representative $e x$-situ, in-situ, and operando Co K-edge X-ray absorption near-edge structure (XANES) spectra for the electrocatalyst films, with the data collected in a manner similar to the Raman spectra in Figure 2a-c. Figure 3d-e presents Co K-edge XANES spectra for Co metal and $\mathrm{CoO}$ standard materials. The ex-situ, in-situ, and operando spectra of the film all exhibited a pre-edge feature near 7711 $\mathrm{eV}$ that was similar to, but less intense than, that of the Co metal standard. This feature can be attributed to metal-to-ligand charge transfer, and resembles the pre-edge feature observed for $\mathrm{Ni} \mathrm{K}$ edge XANES spectra of $\mathrm{Ni}_{2} \mathrm{P}^{28,29}$ The $e x$-situ spectrum also exhibited a white line feature at $7727 \mathrm{eV}$ similar to that observed for the $\mathrm{CoO}$ standard material, indicating the presence of oxidized Co in the as-prepared material that was not detectable by XANES in the active electrocatalyst.

Figure 3f-j presents Fourier-transformed Co K-edge extended $\mathrm{X}$-ray absorption fine structure (EXAFS) data analogous to the XANES data presented in Figure 3a-e. Due to the phase shift, the apparent distance in the Fourier-transformed data is $\sim 0.5 \AA$ shorter than the real distance. ${ }^{30}$ A first-shell distance of $\sim 2.30 \AA$ (apparent distance $\sim 1.8 \AA$ ) was observed for the catalyst was observed during in-situ (Figure 3g) and operando (Figure $3 \mathrm{~h}$ ) analysis, consistent with reported Co-P distances for amorphous Co-P alloys and crystalline $\mathrm{Co}_{2} \mathrm{P} .{ }^{31-33}$ These distances are longer than the typical Co-O distance of $\sim 2.12 \AA$ (as shown in the CoO standard, apparent distance $\sim 1.62 \AA$ ), implying direct Co-P interactions in the first shell. ${ }^{34}$ The in-situ and operando EXAFS provided no indication of long-range order (i.e. no peaks at distances $>3 \AA$ ), suggesting that the catalyst is amorphous under these conditions. The lack of signals indicative of crystallinity is consistent with the Raman spectra. The ex-situ catalyst displayed a slightly different EXAFS pattern (Figure 3f), consistent with a CoP structure mixed with some metallic and oxidized Co as seen by comparison to Co foil and Co oxide standards. The evidence for oxidized Co species in the ex-situ data is also in accord with the Raman analysis. 

(a) CoP: No Electrolyte
(b) - - COP: $0.5 \mathrm{M} \mathrm{H}_{2} \mathrm{SO}_{4}$, open circuit
(c) $0.5 \mathrm{M} \mathrm{H}_{2} \mathrm{SO}_{4}$,
(d) - - Co Standard
(e) CoO Standard

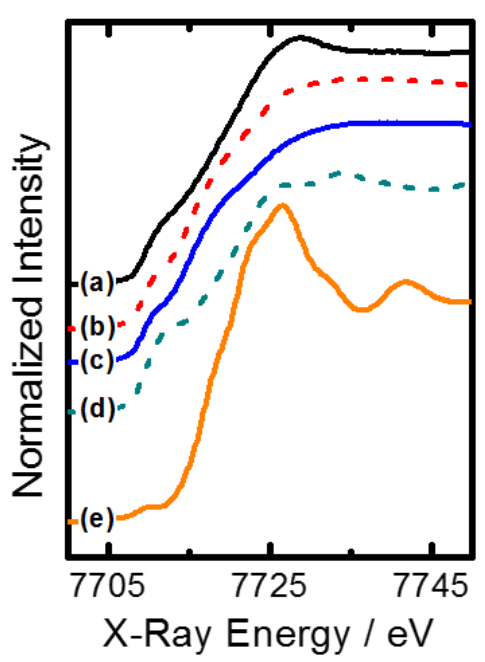

(f) CoP: No Electrolyte

(g) - - CoP: $0.5 \mathrm{M} \mathrm{H}_{2} \mathrm{SO}_{4}$, open circuit

(h) CoP: $0.5 \mathrm{M} \mathrm{H}_{2} \mathrm{SO}_{4}$,

(i) - - Co Standard

(j) $\mathrm{CoO}$ Standard

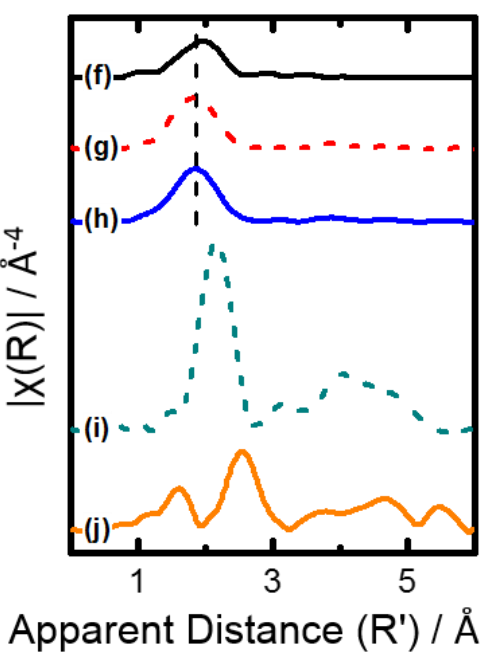

(k) CoP: No Electrolyte

(l) - - CoP: $0.5 \mathrm{M} \mathrm{H}_{2} \mathrm{SO}_{4}$, open circuit

(m) - CoP: $0.5 \mathrm{M} \mathrm{H}_{2} \mathrm{SO}_{4}$, $-0.3 \vee$ vs SCE

(n) $=-\mathrm{K}_{3} \mathrm{PO}_{4}$ Standard

(o) $\mathrm{NaPO}_{2} \mathrm{H}_{2}$ Standard

(p) - - GaP Standard

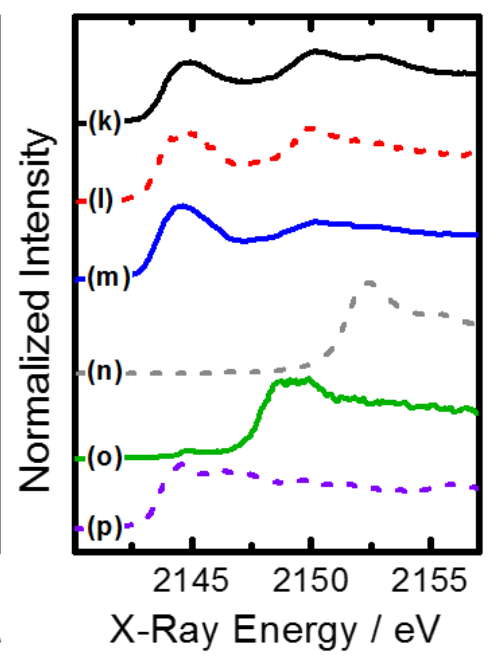

Figure 3. Co K-edge X-ray absorbance nea-edge spectra (XANES) of both CoP films under the indicated conditions and related spectral standards. (a) Spectrum of a CoP film prior to contact with $\mathrm{H}_{2} \mathrm{SO}_{4}$ (aq) (air ambient, ex-situ). (b) CoP film in $0.500 \mathrm{M} \mathrm{H}_{2} \mathrm{SO}_{4}(\mathrm{aq})$ at open circuit (in-situ) (dashed line centered at local spectral maximum). (c) Same as (b) but at an applied potential of -0.300 V vs. SCE (operan$d o$ ). (d) Co and (e) CoO standards. Fourier-transformed Co K-edge extended X-ray absorbance fine structure (EXAFS) data (f)-(j) analogous to the XANES data presented in (a)-(e). P K-edge XANES spectra (k)-(m) analogous to the XANES spectra presented in (a)-(c), and of (n) $\mathrm{K}_{3} \mathrm{PO}_{4}$, (o) $\mathrm{NaPO}_{2} \mathrm{H}_{2}$, and (p) $\mathrm{GaP}$ standards.

(a) Ex-situ

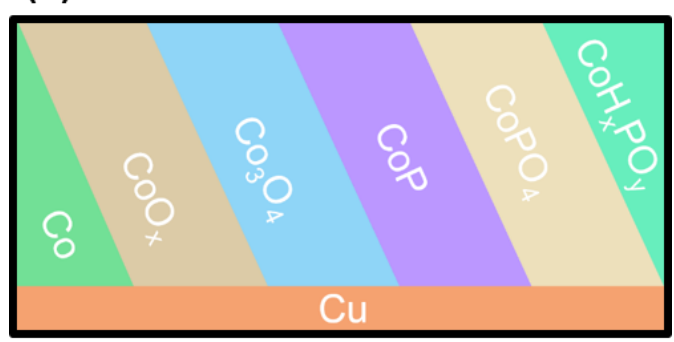

(b) Operando

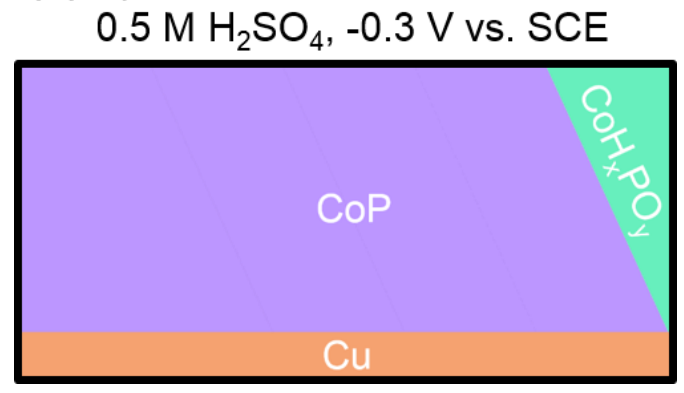

Figure 4. Graphical depictions of the composition of the electrodeposited catalyst film as derived from the cumulative (a) ex-situ analysis as well as from (b) operando analysis in $0.500 \mathrm{M}$ $\mathrm{H}_{2} \mathrm{SO}_{4}(\mathrm{aq})$ at an applied potential of $-0.300 \mathrm{~V}$ vs. SCE.

Figure $3 \mathrm{k}-\mathrm{m}$ presents $\mathrm{P}$ K-edge XANES spectra that are directly analogous to the Co K-edge XANES spectra presented in Figure 3a-c. Additionally, Figure 5d-f displays the $\mathrm{P}$ K-edge XANES spectra for $\mathrm{K}_{3} \mathrm{PO}_{4}, \mathrm{NaPO}_{2} \mathrm{H}_{2}$ and $\mathrm{GaP}$ standard materials. The ex- situ electrocatalyst spectrum exhibited three major features which were centered at $2144.9,2150.2$ and $2152.6 \mathrm{eV}$, respectively. The feature at $2144.9 \mathrm{eV}$ is a close match to that of the $\mathrm{GaP}$ standard, and is consistent with the presence of CoP. The feature at 2152.6 $\mathrm{eV}$ is a close match to the $\mathrm{K}_{3} \mathrm{PO}_{4}$ standard, and is consistent with the presence of a phosphate species in the as-deposited material. The feature at $2150.2 \mathrm{eV}$ is consistent with a phosphorous species having an oxidation state intermediate between phosphide and phosphate. This feature is close to, but not an exact match with, the $\mathrm{NaPO}_{2} \mathrm{H}_{2}$ standard. This standard was unstable under the $\mathrm{X}$ ray excitation, decomposing into a phosphate species that exhibited a characteristic spectral feature near $2152.2 \mathrm{eV}$ as well as a phosphide with a characteristic spectral feature near $2144.9 \mathrm{eV}$ (see Supporting Information for details). This instability precluded definitive determination of the precise energy of the $\mathrm{NaPO}_{2} \mathrm{H}_{2}$ spectral feature, but suggests a value of $\sim 2149.4 \mathrm{eV}$. The asprepared film may contain $\mathrm{P}$ in an oxidation state intermediate between that of it in $\mathrm{NaPO}_{2} \mathrm{H}_{2}$ and in $\mathrm{K}_{3} \mathrm{PO}_{4}$. Hence, the $\mathrm{P} \mathrm{K}$-edge XANES spectra indicated that the as-deposited material contained $\mathrm{P}$ in several oxidation states, consistent with the prior XPS analysis. Relative to the ex-situ spectrum, in the in-situ and operando spectra the spectral features at $2152.6 \mathrm{eV}$ and $2150.2 \mathrm{eV}$ were attenuated, while the feature at $2144.9 \mathrm{eV}$, attributed to $\mathrm{P}$ in a phosphide form, increased in intensity. These data thus indicate that the oxidized $\mathrm{P}$ species were reduced to phosphide during operation, and suggest the active electrocatalyst is predominantly composed of $\mathrm{P}$ in a reduced oxidation state. This behavior is consistent with the Raman analysis, wherein signals ascribable to oxidized P species were only observed in the ex-situ examination of the as-prepared material. The cumulative data, represented graphically in Figure 4, thus suggest that although ex-situ analysis of the electrodeposited film indicated a material composed of 
multiple phases with $\mathrm{Co}$ and $\mathrm{P}$ both existing in several oxidation states, the active electrocatalyst is an amorphous material composed of Co in a near-zero valent state and $\mathrm{P}$ in a reduced state. A material synthesis that ensures production of solely a metal phosphide phase as the initial film composition therefore does not appear to be necessary for producing an effective CoP-based HER electrocatalyst.

In summary, voltammetric analysis indicated that films electrodeposited from an aqueous solution containing $\mathrm{CoCl}_{2}$ and $\mathrm{Na}$ $\mathrm{PO}_{2} \mathrm{H}_{2}$ were active HER electrocatalysts, capable of effecting a $10 \mathrm{~mA} \mathrm{~cm}{ }^{-2}$ current density towards the HER at $-\eta<100 \mathrm{mV}$ in $0.500 \mathrm{M} \mathrm{H}_{2} \mathrm{SO}_{4}(\mathrm{aq})$. Ex-situ Raman analysis of as-deposited material indicated the presence of several oxidized Co species, including crystalline $\mathrm{Co}_{3} \mathrm{O}_{4}$, as well as oxygenated $\mathrm{P}$ species, but the associated spectroscopic signatures were not observed during operando analysis. No phonon scattering was observed during operando Raman analysis. Ex-situ Co K-edge and P K-edge XANES spectra also indicated the presence of oxidized Co and $\mathrm{P}$ species in addition to a near-zero valent Co species and a reduced $\mathrm{P}$ species. Operando XANES data exhibited a pronounced decrease in the absorption edges of oxidized $\mathrm{Co}$ and $\mathrm{P}$ species. Additionally, ex-situ Co K-edge EXAFS data indicated the presence of a crystalline, oxidized Co-containing phase, but, as in the Raman analysis, this signal was not observed during operando analysis. The collective spectroscopic evidence thus indicates that the active electrocatalyst is an amorphous material consisting of Co in a near-zero-valent state and $\mathrm{P}$ in a reduced state.

\section{ASSOCIATED CONTENT}

\section{Supporting Information}

The Supporting Information is available free of charge on the ACS Publications website. Details regarding experimental methods, additional standard P K-edge X-ray absorption spectra, and related references (PDF)

\section{AUTHOR INFORMATION}

\section{Corresponding Authors}

*jyano@lbl.gov

*msoriaga@caltech.edu

*nslewis@caltech.edu

\section{Author Contributions}

- These authors contributed equally (FHS and AIC).

\section{Notes}

The authors declare no competing financial interests.

\section{ACKNOWLEDGMENT}

This work was based on work performed by the Joint Center for Artificial Photosynthesis, a DOE Energy Innovation Hub, supported through the U. S. Department of Energy Office of Science under Award Number DE-SC0004993. Synchrotron measurements were performed at beamlines 7-3 and 14-3 at the Stanford Synchrotron Radiation Lightsource at SLAC National Accelerator Laboratory, which is operated by Stanford University for the U.S. Department of Energy Office of Science, Office of Basic Energy Sciences, under Contract No. DE-AC02-76SF00515, and supported by the Office of Biological and Environmental Research, and by the NIH including P41GM103393. AIC acknowledges a Graduate Research Fellowship from the National Science Foundation. The authors gratefully acknowledge R. Jones and Dr. K. Walczak for assistance with spectroelectrochemical cell fabrication.

\section{REFERENCES}

(1) Ursúa, A.; Gandía, L. M.; Sanchis, P. Proc. IEEE 2012, 100, 410-426.

(2) Turner, J.; Sverdrup, G.; Mann, M. K.; Maness, P.-C.; Kroposki, B.; Ghirardi, M.; Evans, R. J.; Blake, D. Int. J. Energy Res. 2008, 32, 379407.

(3) Cook, T. R.; Dogutan, D. K.; Reece, S. Y.; Surendranath, Y.; Teets, T. S.; Nocera, D. G. Chem. Rev. 2010, 110, 6474-6502.

(4) Pentland, N.; Bockris, J. O.; Sheldon, E. J. Electrochem. Soc. 1957, 104, 182-194.

(5) Lee, T. S. J. Electrochem. Soc. 1971, 8, 1278-1282.

(6) Schuldiner, S. J. Electrochem. Soc. 1952, 99, 488-494.

(7) McKone, J. R.; Marinescu, S. C.; Brunschwig, B. S.; Winkler, J. R.; Gray, H. B. Chem. Sci. 2014, 5, 865-878.

(8) Soriaga, M. P.; Baricuatro, J. H.; Cummins, K. D.; Kim, Y.-G.; Saadi, F. H.; Sun, G.; McCrory, C. C. L.; McKone, J. R.; Velazquez, J. M.; Ferrer, I. M.; Carim, A. I.; Javier, A.; Chmielowiec, B.; Lacy, D. C.; Gregoire, J. M.; Sanabria-Chinchilla, J.; Amashukeli, X.; Royea, W. J.; Brunschwig, B. S.; Hemminger, J. C.; Lewis, N. S.; Stickney, J. L. Surf. Sci. 2015, 631, 285-294.

(9) Zou, X.; Zhang, Y. Chem. Soc. Rev. 2015, 44, 5148-5180.

(10) Choquette, Y.; Brossard, L.; Lasia, A.; Ménard, H. Electrochim. Acta 1990, 35, 1251-1256.

(11) Brown, D. E.; Mahmood, M. N.; Man, M. C. M.; Turner, A. K. Electrochim. Acta 1984, 29, 1551-1556.

(12) McKone, J. R.; Sadtler, B. F.; Werlang, C. A.; Lewis, N. S.; Gray, H. B. ACS Catal. 2013, 3, 166-169.

(13) Carmo, M.; Fritz, D. L.; Mergel, J.; Stolten, D. Int. J. Hydrogen Energy 2013, 38, 4901-4934.

(14) Popczun, E. J.; McKone, J. R.; Read, C. G.; Biacchi, A. J.; Wiltrout, A. M.; Lewis, N. S.; Schaak, R. E. J. Am. Chem. Soc. 2013, 135, 92679270.

(15) Shi, Y.; Zhang, B. Chem. Soc. Rev. 2016, 45, 1529-1541.

(16) Popczun, E. J.; Read, C. G.; Roske, C. W.; Lewis, N. S.; Schaak, R. E. Agnew. Chem., Int. Ed. 2014, 53, 5427-5430.

(17) Callejas, J. F.; McEnaney, J. M.; Read, C. G.; Crompton, J. C.; Biacchi, A. J.; Popczun, E. J.; Gordon, T. R.; Lewis, N. S.; Schaak, R. E. ACS Nano 2014, 8, 11101-11107.

(18) Liu, Q.; Tian, J.; Cui, W.; Jiang, P.; Cheng, N.; Asiri, A. M.; Sun, X. Agnew. Chem., Int. Ed. 2014, 53, 6710-6714.

(19) Jiang, P.; Liu, Q.; Liang, Y.; Tian, J.; Asiri, A. M.; Sun, X. Agnew. Chem., Int. Ed. 2014, 53, 12855-12859.

(20) Saadi, F. H.; Carim, A. I.; Verlage, E.; Hemminger, J. C.; Lewis, N. S.; Soriaga, M. P. J. Phys. Chem. C 2014, 118, 29294-29300.

(21) Tyczkowski, J.; Kapica, R.; Łojewska, J. Thin Solid Films 2007, 515, 6590-6595.

(22) Hadjiev, V. G.; Iliev, M. N.; Vergilov, I. V. J. Phys. C Solid State Phys. 1988, 21, L199-L201.

(23) Frost, R. L. Spectrochim. Acta Mol. Biomol. Spectrosc. 2004, 60, 1439-1445.

(24) Mitchell, P. C. H.; Parker, S. F.; Simkiss, K.; Simmons, J.; Taylor, M. G. J. Inorg. Biochem. 1996, 62, 183-197.

(25) Bell, R. M.; Jeppesen, M. A. J. Chem. Phys. 1935, 3, 245-247. (26) Cox, R. A.; Haldna, Ü. L.; Idler, K. L.; Yates, K. Can. J. Chem. 1981, 59, 2591-2598.

(27) Pourbaix, M. Atlas of Electrochemical Equilibria In Aqueous Solutions; Permagon Press: Oxford, 1966.

(28) Bando, K. K.; Wada, T.; Miyamoto, T.; Miyazaki, K.; Takakusagi, S.; Koike, Y.; Inada, Y.; Nomura, M.; Yamaguchi, A.; Gott, T.; Ted Oyama, S.; Asakura, K. J. Catal. 2012, 286, 165-171.

(29) Kawai, T.; Sato, S.; Chun, W. J.; Asakura, K.; Bando, K. K.; Matsui, T.; Yoshimura, Y.; Kubota, T.; Okamoto, Y.; Lee, Y. K.; Oyama, T. S. Phys. Scr. 2005, 2005, 822-824.

(30) Koningsberger, D. C.; Mojet, B. L.; van Dorssen, G. E.; Ramaker, D. E. Top. Catal. 2000, 10, 143-155.

(31) Cargill, G. S.; Cochrane, R. W. J. Phys. Colloques 1974, 35, C4-269C264-278.

(32) Chi, G. C.; Cargill Iii, G. S. J. Appl. Phys. 1979, 50, 2713-2720.

(33) Rundqvist, S. Acta Chem. Scand. 1960, 14, 1961-1979.

(34) Redman, M. J.; Steward, E. G. Nature 1962, 193, 867. 


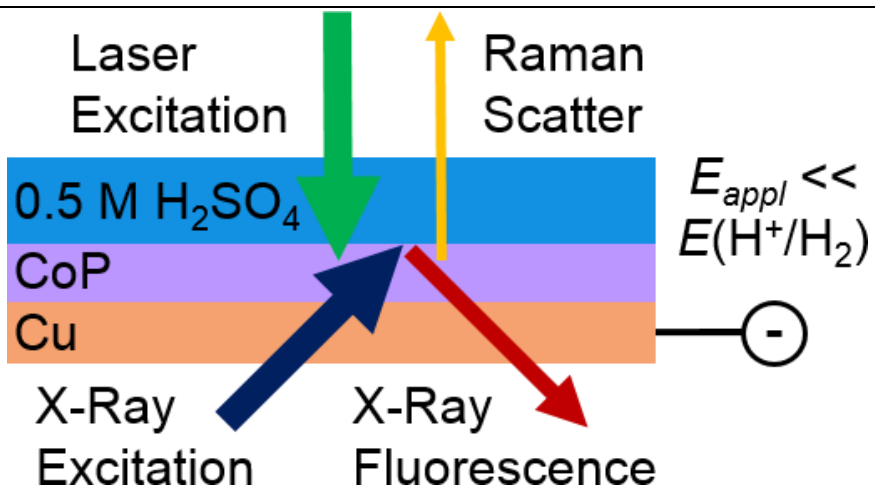

